\title{
THE CASE OF A CHILD WITH AUTISTIC MANIFESTATIONS WHO BELIEVES IN THE PROMISE
}

\author{
J. Gospodinova, K. Gospodinov, V. Gonchev, A. Halil \\ Home for Medical and Social Care for Children - Kardzhali, Bulgaria \\ Universety Assen Zlatarov, Burgas, Bulgaria
}

\begin{abstract}
Lea is a child of 2 years old, housed in HMSCC in Kardzhali, and subsequently abandoned by the mother in the institution where she lives until now. Up to 3 months old, he spends most of his time sleeping and eating. After an active stimulation aimed at tracking a shining slow-moving object, the child became intrigued by him and showed he was watching him, and then turning his head. He found his hands as parts of his body and began to watch them for a long time. He did not develop a "revival complex" despite the system's psychological emotional and social impact. When she started to turn from her back to her stomach, her swinging and "incontinence" on her head was irritating.
\end{abstract}

Key words: emotional deficiency, psycho-motor development

Lea is a child of 2 years and 3 months, housed for cultivation in Home for medical and social care for children - Kardzhali and subsequently abandoned by the mother in the institution where she lives until now. Her mother visits her, according to the scheme of visits made by her social worker, but when the girl is 6 months old, she appears to be seeing her mother for the last time. At this last meeting, she promises to Little Lea that when her father returns from Germany and repairs their apartment in Bourgas, she will take her home.

At 7 months of age, Lea began to notice a lag in her psychomotor development. It does not crawl, with unstable head control and no stable footrest. Do not report pathological reflexes. Her muscular tone is unbalanced. Weak muscles are flexors, expanders, abductors, adductors, external and internal rotators of the shoulder, hock, hip, knee and ankle joints, flexors and extensors of the corpse, neck and abdominal wall. A rehabilitation activity is started with the child aiming to improve its condition. When Lea is at the age of 10 months, development progresses, which is again followed by stagnation. It provides guidance and research. Reaction to loud sounds. In the case of auditory stimulation, he stops his motor activity. She does not concentrate on looking at the adult who is bent over her and speaks to her. After prolonged stimulation, it briefly establishes visual contact by looking sharply through the other.
Playing with a toy is a long way. Do not participate in situations of "shared attention" through object manipulations. It should be borne in mind that when the significant other responds to the visceral reactions of the child, he takes these reactions as a call to him and thus projects the child into the world of interpersonal communication. The mother's deputy's response to the child's needs allows for a shift from tension to relaxation. By interpreting Leah's cries and excitement as a call, the personally responsible adult gives them a sense of communication. The child does not react intensively in accordance with their urgent needs. In this context there is a nonharmonious recording of emotions in communication with the other. Prefer activities with objects in front of emotional and social impacts. In tactile stimulation he laughs aloud. When analyzing the interactions, emphasis should be placed on the absence of synchronicity in sight contact, reciprocity. It shows insufficient sensitivity, lacking readiness for interaction; active avoidance of sight. He looks at a new object. She touches both hands on her subject. Involved in sensory games: visual-auditory, tactile, built between the child and the elderly. Gradually, the child moves from the occasional flinching of her hand to her careful examination. He wants to do something so something happens he hits an object to continue the induced pleasant incentive. Lea vocalizes long when she is alone. It does not present early identification with another 
GOSPODINOVA J., et al.

person and imitation of mimic movements. When the girl is 1 year and 5moths begins to stand vertically to a knee position. Her emotional and social development is characterized by deficits and inconsistencies in age standards. He attempts to stand up, grasping for a fixed support, tapping one leg in the hip and knee joint. Taking a vertical posture and maintaining balance is unstable. The pelvis is in inclination. The feet are in full extension to knee joint hyperextension. Ischocrural muscles are weak and stretched. Badly coordinated movements of the body. Holding under the armpits, makes slow and uncertain steps. Muscles that support the dynamic equilibrium of the posture in the frontal and sagittal plane are the weak muscles which are the muscles of the corpus extenders, hip extensors, abdominal muscles, flexors in the hip, abductors and adductors, prostheses and knee joint supporters. there are considerable difficulties in maintaining a balance in the right position. Lordship is more pronounced during standing. Lea does not yet show that she has developed emotional attachment. He does not prefer the human face, he avoids mutual consideration. He does not present a social smile. Missing voices are missing; gestures to attract attention and contact with the adult; it does not stretch forth his hands to be taken away; does not recognize strangers and does not become distrustful or alarming in the presence of strangers. He uses a rattle for security and comfort. Does not interact with another person, does not explore an object with him. She does not stand alone by holding furniture, modules, not walking alone. Regarding selfawareness and building identity, it is at the level of transition from accidental slapping and sucking to the careful examination. Exploration and autonomy are found in the feeding of fingers to their mouths and observation of their hands and movements.

Lea's assessment of mental development is made by describing and explaining its general changes in the process of knowledge in the context of an explanation of the Paige intelligence genesis. The achievements of the child refer to the 3rd stage of intellectual development (according to the defined periods of the Swiss psychologist), to the third stage of the senso-motor period in which "secondary circular reactions" occur, which are already spread to external objects. Through it, there is coordination between vision and grip. The child does not look for the subject that has disappeared from his field of vision, ie. it did not realize the "constancy of the object". By the end of the analyzed period, specific interests and rituals have begun to be observed in the child. It can be "swallowed" for a long time by a part of a toy or by the edge of a certain surface. He does not communicate verbally, does not imitate and does not show with his behavior that he understands the speech addressed to him.

In the interaction analysis (Mannheim Scale, Esmer et al.), the following scales of the interaction disturbances are differentiated: insufficient reactivity/sensitivity; lack of readiness for interaction - active avoidance of sight. Look looks at the sides. Vocalization - neutral / positive. Gestures - reach one hand; tilts forward; stereotyped / weird gestures. Self-restraint - Oral your finger; Oral - subject; touching oneself; patting/clapping - to yourself; swinging. Distance - curves; repels, repels. The actions she uses are learned by exploring the mechanical world, not by imitating the actions of others. Does not understand a simple cause / effect relationship.

During awakening, Lea is busy with an object or with parts of her own body: the arms or legs that are moving up and down. These separate objects or parts of the body in the context of Eric Laurent's interpretation are added to the body as a supplementary organ with which the little girl is difficult to separate. A material object, sometimes even a corporeal object, is considered, and since it does not pass through the language or is said to be a real object. He uses it for manipulation by upand-down moves or by moving the rattle, which makes it possible to alternate noise - silence. She is totally absorbed in this activity, but Lea does not even speak on her subject, nor talk about it, even in the rare moments where vocals are pronounced, and at the moment - and several random sounds. This treatment of the rattle-type manipulation also does not pass through speech and can be called real. But the manipulation of the object is done by a stroke or movement divided into two times. This movement, this alternation has the structure of language. Thus, through a real object and through a real manipulation, Lea tries to include the symbolic thing, which has value.

From the age of 6 months to 18 months, the child who sees his image in the mirror has a strong joy. His image in the mirror gives him a complete picture of his body, which he feels fragmented because of his immaturity. Lea does not identify with the image he sees in the mirror and does not turn to the adult who carries it to find a sign of achievement in his eyes. The girl has not conquered the unity of her own body, it is not recognized in the mirror. A very important object circulating between the child and the elderly is the look. The look and what he can bring to the other. Sometimes there is a feeling that she watches you for a moment, but Lea looks in a disturbing and fixating way. It seems conscious that it avoids the 
other aspect of the eye, that when you are in the sight of someone else and when someone else is watching you, in his gaze you find yourself loved. Lea tells us a different path than the search for another. This time is the path of a "peculiar partner" you find - that is the thumb that puts in your mouth and thus cancels the human presence.

\section{CONCLUSIONS}

1. The child has a slow start in maturation and development most likely caused by early deprivation of maternal care, emotional deficiency and has not compensated for the missing stages of psycho-motor development, both in terms of motor and cognitive abilities, and socio-communicative skills.

2. Due to weak muscle groups, it lags behind in its motor development. Impossibility to occupy a vertical position alone up to the age of 1year and 5months. Damaged fine motorcycle. At age 2 years and 1 month. Lea manages 3-4 paces alone.

3. There is no age-appropriate development of the intellect, which explains the impossibility of normal intellectual functioning. Cognitive abilities are below expectations for the age.

Lea's behavior is characterized by selfstimulation, absent regulation, and context reporting. She has not made attachment. In the hypothesis of the child's psychologist, it is
GOSPODINOVA J., et al. important that Little Lea presents a clinical picture hat does not correspond to any accurate diagnosis in the current research. The absence of this knowledge makes it possible to look for this unintelligent child the words and images on which it can rely on its mental suffering. But Lea believes in the promise of someone else. She has stayed too long in anticipation and that's why her awakening is so late. At the moment she is aged 2 years. $3 \mathrm{~m}$. and stabilizes self-walking. Now it is often occupied with an object - it can be the edge of the cube that she is looking at at an angle. The subject of Lea is partial - it can be glued to the slipper, which the child continuously peels off and sticks to. This manipulation of object-type manipulation does not go through speech. A method based on the symptomatic features presented by Lea is applied by the consultant to the child. His specificity is that he takes institutional changes from the exact study of what Lea suffers on one hand and on the other, according to the logic of the meeting, he depends on the personal style of the psychologist who is in the situation to meet in at some point the child's suffering after the sudden disappearance of the mother after the promise given by words to return to the 6-month-old Lea. From that point on, she presents symptoms that affect all the situations in which the child has to deal with the request: nutrition, language, relationships with others, exchange of views. 